\title{
In vitro Anti-Cancer Activity of Rosuvastatin and Ketorolac Nanoformulations against DDX3
}

\author{
Khaggeswar Bheemanapally', Manish Kumar Thimmaraju², Sagar Kasagoni², Prathyusha Thatikonda ${ }^{2}$, Swathi Akula', Kranthi Raj \\ Kodamala ${ }^{3}$, Lavanya Kakarla ${ }^{3}$, Sridhar Babu Gummadi ${ }^{4}$, Harishankar Nemani ${ }^{5}$, Mahendran Botlagunta ${ }^{3,6 *}$ \\ 'Balaji Institute of Pharmaceutical Sciences, Warangal, Telengana-506331, INDIA. \\ 2Balaji Institute of Pharmacy, Warangal, Telengana-506331, INDIA. \\ 3Department of Biotechnology, K L University, Guntur, Andhra Pradesh-522502, INDIA. \\ ${ }^{4}$ Sri Shivani College of Pharmacy, Warangal, 506007, INDIA. \\ 5 National Centre for Laboratory Animal Sciences, National Institute of Nutrition, ICMR, Taranaka, Hyderabad, Telangana, INDIA. \\ ${ }^{6}$ Sweety Biologicals India Private Limited, Kavali, Andhra Pradesh-524201, INDIA.
}

\begin{abstract}
Background: DDX3 is the human RNA helicase and enhanced expression of DDX3 protein was found in several cancers including leukemia. Statin family of drugs shown to inhibit the growth of acute myeloid leukemia cells. Objective: In this paper we report the molecular interaction of Rosuvastatin Calcium (RST) salt with DDX3 by Molecular docking. Molecular dynamics simulation (MDS) using Desmond further confirmed that the RST forms strong intra and inter molecular hydrogen bond network with DDX3 as similar to Ketorolac salt, a known inhibitor of DDX3. Materials and methods: To validate the biological activity, RST and KT nanoemulsions were prepared using propylene glycol monocaprylate (type II) NF, glycerol monolinoleate EP, Lauroyl macrogol-6 glycerides EP and poloxamer 188 to improve the bioavailability in rats. Solution state stability study was performed at various $\mathrm{pH}$ for $24 \mathrm{~h}$ to determine the integrity of RST and KT in nanoemulsion formulations. The prepared formulations have been evaluated for permeability across porcine buccal membrane. The RST and KT nanoemulsions were evaluated for anticancer activity using K-562 leukaemia cancer cell lines. Results: It showed both the nanoemulsions inhibited the
\end{abstract}

growth of the cancer cell and also reduced the expression of DDX3 protein. Bioavailability study in rats revealed that nanoemulsion formulations have exhibited higher systemic concentrations. Conclusion: In summary, taken together, our result demonstrates, for the first time, inhibition of DDX3 expression by RST nanoemulsions indicates that this nanoformulation can be used as an ideal drug candidate to treat DDX3 associated blood cancer. Key words: Rosuvastatin, Ketorolac salt, Nanoformulations, DDX3, Molecular docking and anti cancer activity.

Correspondence :

Dr. Mahendran Botlagunta, Associate Professor, Biomedical Research Laboratory, Department of Biotechnology, K L University, Green fields, Guntur district, Andhra Pradesh-522502 INDIA.

Phone: 07382145827

Email: bmnchowdary@gmail.com or drmahi_bt@kluniversity.in

DOI: 10.5530/jyp.2017.9.103

\section{INTRODUCTION}

Human DDX3 gene encodes a polypeptide of 662 amino acids and this protein plays an important role in several aspects of RNA metabolism. ${ }^{1,2}$ This protein has two clear distinguishable domains comprised of $\mathrm{N}$-terminal DEAD box domain 1 (211-403 residues) and C-terminal helicase domain 2 (411-575 residues). Both domains displayed RecA-like folds comprising a central $\beta$-sheet flanked by $\alpha$-helices connected by a noncanonical linker of 11 amino acids. ${ }^{3}$ Expression of DDX3 was detected in several tissues such as testis, colon, lung, liver, skeletal muscle, and kidney ${ }^{2,4}$ indicating the universal role of DDX3 in cellular homeostasis. Moreover, elevated expression of DDX3 was found in a highly aggressive metastatic breast cancer cell line, MDA-MB-231, as compared with non-metastatic MCF-7 cells, which show its potential role in aggressive breast cancers and associated metastasis. ${ }^{5,6}$ We have previously reported that overexpression of DDX3 in immortalized non-turmorigenic MCF10A cells promoted neoplastic transformation as indicated by down regulation of a cell adhesion molecule, E-cadherin. ${ }^{5}$ Down-regulation of E-cadherin is a common feature of a variety of metastatic epithelial tumors, including those of the lung, breast and prostate cancer. ${ }^{5,7-9}$ Hypoxic regions of solid tumors were considered to be the primary sites for the generation of the metastatic phenotype and have been demonstrated to be chemo and radio-resistant. ${ }^{10-14}$ We have also reported that hypoxia inducible factor (HIF-1) induce the expression of DDX3 in two different breast cell lines by binding directly or indirectly to the hypoxia-response element (HRE) in the DDX3 proximal promoter. ${ }^{15}$ On the other hand, a significant down regulation of DDX3 expression is found in hepatocellular carcinoma (HCCs) from the hepatitis B virus (HBV) positive patients, but not from HCV positive in comparison to the corresponding non tumor tissues. ${ }^{16}$ In the hepatocellular carcinoma model, DDX3 was found to act as a tumor suppressor by activating the expression of cyclin dependent kinase inhibitor p $21^{\text {cip } 1} \cdot{ }^{17}$ Besides cancer, induced expression of DDX3 was also found in HIV-1 infected cells. ${ }^{18,19}$ Overall, it suggests that DDX3 is a multifunctional protein and it plays a specific role in regulatory mechanisms and signaling pathways. Apart from embryonic development, this gene is also involved in multiple diseases like HIV, Neuro-degenerative diseases, hepatocellular carcinoma and brain and breast cancer. Several Synthetic compounds have been discovered to inhibit the function of DDX3 by blocking the function of helicase activity. ${ }^{20-24}$ Synthetic drugs are those substances that are produced entirely from chemical reactions in a laboratory. Synthetic drugs most often have shown to suppress the immune system by paralyzing the bone marrow. ${ }^{25,26}$ Moreover, it takes an average of about 8 to 12 years from the time a cancer drug enters into clinical trials from the research lab. ${ }^{27,28}$ Therefore, we focused to identify FDA approved drugs against DDX3. In our continuing efforts, we have found that Rosuvastatin (RST) and Ketorolac (KT) salt form strong hydrogen bond

This is an open access article distributed under the terms of the Creative Commons Attribution-NonCommercial-ShareAlike 4.0 License, which allows others to remix, tweak, and build upon the work non-commercially, as long as the author is credited and the new creations are licensed under the identical terms. 
interactions with crystallized form of DDX3 using in-silico molecular docking approach. Rosuvastatin is an inhibitor of HMG-CoA reductase, a major rate-limiting enzyme in cholesterol biosynthesis belongs to the family of statins. And it has been shown to induce the expression of the low-density lipoprotein (LDL) receptor which mediates the clearance of LDL cholesterol from plasma. Compared with other statins, Rosuvastatin is more efficient and shown to exhibit fewer side effects. ${ }^{29}$ Ketorolac salt is a pyrrolizine carboxylic acid derivative and belongs to the family of non-steroidal anti-inflammatory drugs (NSAIDs), which are mainly used for the treatment of inflammation and pain after surgery. ${ }^{30}$ Both RST and KT were encapsulated using pharmaceutical excepients such as propylene glycol monocaprylate (type II) NF, glycerol monolinoleate EP, Lauroyl macrogol-6 glycerides EP and poloxamer 188. Bioavailability of these nanoemulsions was tested in in-vivo animal models. Both the nanoemulsions displayed anti-cancer activity against K-562 leukemia cancer cell lines.

\section{MATERIALS AND METHODS}

Rosuvastatin calcium and Ketorolac Tromethamine was obtained as gift sample from Nosch labs Pvt. Ltd., India. Labrafil M2130CS (Lauroyl macrogol-6 glycerides EP), Capryol 90 (Propylene glycol monocaprylate (type II) NF), Maisine 35-1 (Glycerol monolinoleate EP) were obtained as gift sample from Gattefosse. Poloxamer 188 was obtained as gift sample from BASF Corporation North America. Acetonitrile and methanol HPLC grade were purchased from SD Fine Chemicals Mumbai. In house triple, distilled water was used throughout the study.

\section{Molecular Docking and Molecular dynamic simulations}

Molecular dynamic simulations were performed for the insights of complexes stability using Desmond ${ }^{31}$ with OPLS (Optimized Potentials for Ligand Simulations) 2005. ${ }^{32}$ Before starting simulations, human DEAD Box RNA Helicase (DDX3) 3,33 $^{3}$ was first prepared using protein preparation wizard in Maestro 9.3.5. Induced fit docking (IFD) ${ }^{34}$ was performed to find the better orientation and conformation of the compounds (Rosuvastatin and Ketorolac) in binding pocket. Complexes were loaded into Desmond that works using Maestro interface. Protein was soaked with TIP4P water model in orthorhombic box. Counter ions were used appropriately for neutralizing the system. 5000 iterations were fixed for minimizing the energy of the complexes using steepest descent method until it reached $25 \mathrm{kcal} / \mathrm{mol} / \AA ̊$ gradient threshold and $1 \mathrm{kcal} / \mathrm{mol} / \AA$ convergence threshold. Equilibration of systems was carried by default parameters. Equilibrated systems were simulated at constant temperature of $300 \mathrm{k}$ and constant pressure of $1 \mathrm{~atm}$. A $10 \mathrm{~ns}$ molecular dynamic simulation (MDS) was performed for the protein ligand complexes. Energy of the complexes was analyzed for both the complexes. RMSD (Root Mean Square Deviation) and RMSF (Root Mean Square fluctuation) of the complexes were calculated for the entire trajectory comparing with its initial frames. Intra and inter molecular hydrogen bonding network was analyzed for knowing the stability of compounds in a better way.

\section{Preparation of RST and KT nanoemulsions}

The nanoemulsions were prepared by using high speed homogenizer followed by ultrasonication. Excess RST was added to the components of oil, surfactant and cosurfactant and then water was added drop wise with continuous stirring for $45 \mathrm{~min}$ at $12000 \mathrm{rpm}$. All formulations comprise of $20 \mathrm{mg}$ of RST, $350 \mathrm{mg}$ of Poloxamer 188 as surfactant and $350 \mathrm{mg}$ of Labrafil M2130CS as cosurfactant. Similarly, $20 \mathrm{mg}$ of KT was taken along with said surfactant and cosurfacatnt Table 1. Briefly, the RST and KT nanoemulsions were prepared using IKA- Ultra-Turrax T25 (IKA Labortechnik, Staufen, Germany) at $12000 \mathrm{rpm}$ by adding required quantity of RST to oil and further surfactant and cosurfactant were added in the ratio of $1: 1$. Water was added to the mixture gradually during homogenization. The excess drug was removed by centrifugation. Furthermore, ultrasonication was performed at amplitude of $30 \%$ for 4 min (Pulse on $2 \mathrm{sec}$ and Pulse off $3 \mathrm{sec}$ ). The undissolved drug was removed by filtration using $0.45 \mu \mathrm{m}$ membrane. The concentration of drug in the filtrate was measured using HPLC using Binary LC-20AD pump and SPD-20A UV/VIS prominence detector (Shimadzu, Kyoto, Japan), chromatographic column C-18 (5 $\mu \mathrm{m}, 250 \mathrm{~mm} \times 4.6 \mathrm{~mm})$. For HPLC, Mixture of acetonitrile: water and methanol: water was used as the mobile phase for RST and KT in the ratio of 65:35 (v/v) respectively. The flow rate was $1 \mathrm{ml} / \mathrm{min}$; RST and KT were detected at a wavelength of $243 \mathrm{~nm}$ and $320 \mathrm{~nm}$. The nanoemulsions were stored in freezer at 10 $15^{\circ} \mathrm{C}$ until used.

\section{Determination of drug content}

The prepared formulations were tested their drug content. Three samples $(n=3)$ each of $10 \mathrm{mg}$ was collected from each formulation and diluted to suitable volume with respective mobile phases and kept vortex for 2 min to ensure complete dispersibility. Then the contents were clarified using $0.22 \mu \mathrm{m}$ millipore membrane and injected into HPLC instrument.

\section{Determination of viscosity}

The viscosity of RST and KT formulations were determined using Brookfield viscometer (Brookfield DV-II Pro Viscometer) with spindle Ultra Low Adapter (ULA) at $25^{\circ} \mathrm{C}$. The data acquisition was achieved with Rheocalc 32 software. The rate of shear (rpm of spindle) was gradually increased to attain higher torque (force required to rotate the spindle). The higher torque value (90-100\%) represents the certain viscosity of the sample.

\section{Solution state stability of formulations at various $\mathrm{pH}$}

RST and KT were prepared at a concentration of $1 \mathrm{mg} / \mathrm{mL}$ with acetonitrile, $10 \mathrm{mg}$ of formulations of R-1, R-2, K-1 and K-2 was further diluted with acetonitrile. These were further diluted with various buffers of $\mathrm{pH} 1.2$, $4,6.8,7$ and 7.5 , each to $10 \mathrm{~mL}$ and incubated for 1,2 and $24 \mathrm{~h}$ at $37^{\circ} \mathrm{C}$. The developed HPLC analytical method was used to determine the drug content in RST, KT and respective formulations.

\section{In vitro release kinetics}

In vitro release studies of RST and KT nanoemulsion formulations were performed using Franz diffusion cell. The donor and acceptor compartment

Table 1: Composition (in mg) of RST and KT loaded Nanoemulsions

\begin{tabular}{cccccccc}
\hline Formulation & RST & KT & Capryol 90 & Maisine 35-1 & Poloxamer 188 & Labrafil M2130CS & Water \\
\hline R-1 & 20 & - & 300 & - & 350 & 350 & 600 \\
R-2 & 20 & - & - & 300 & 350 & 350 & 600 \\
K-1 & - & 20 & 300 & - & 350 & 350 & 600 \\
K-2 & - & 20 & - & 300 & 350 & 350 & 600 \\
\hline
\end{tabular}


capacity were $5 \mathrm{~mL}$ and $20 \mathrm{~mL}$ respectively. The acceptor compartment was filled with phosphate buffer $\mathrm{pH} 6.8$ to simulate buccal and intestinal environments. Freshly activated dialysis membrane (MWCO 12,000$14,000 \mathrm{Da})$ was clamped in between the donor and acceptor chamber of Franz diffusion cell. ${ }^{35}$ The study was conducted for a period of $2 \mathrm{~h}$ in which samples were withdrawn at 10, 20, 30, 45, 60, 90 and $120 \mathrm{~min}$ respectively. Every sample of $1 \mathrm{~mL}$ at each time interval from diffusion cell withdrawn is replaced with $1 \mathrm{~mL}$ of fresh phosphate buffer $\mathrm{pH} 6.8$ to maintain sink condition. The collected sample was further diluted with selected mobile phase and analyzed using HPLC. The cumulative \% drug release vs. time profiles of RST and KT were plotted.

\section{Buccal membrane permeability studies}

The barrier nature of the biological tissues can be determined using drug permeability studies under controlled variables like $\mathrm{pH}$, temperature and osmolarity. ${ }^{36-39}$ In our present study, porcine was used as model for permeation of drug formulation across buccal membrane. The prepared formulations were further evaluated for permeation across the porcine buccal membrane using Franz diffusion cell. ${ }^{37}$ The permeation study was performed using phosphate buffer $\mathrm{pH} 6.8$ to simulate buccal environments. The quantity of samples of $1 \mathrm{~mL}$ was withdrawn at $10,20,30$, 45, 60, 90 and $120 \mathrm{~min}$ and replaced with fresh phosphate buffer $\mathrm{pH}$ 6.8. The withdrawn samples were diluted with selected mobile phase and analyzed using HPLC. The cumulative \% drug release vs. time profiles of RST and KT were plotted.

\section{Determination of HLB Values}

Hydrophile-lipophile balance (HLB) method was devised by Griffin to classify the surfactants. HLB represents a scale of surfactant hydrophilicity ranges from 0 to 20. Surfactants with a HLB value below 6 tend to provide stable water-in-oil emulsions and those with a HLB value above 8 tend to stabilize oil-in-water emulsions. Based on the different HLB values of various surfactants, the resulting HLB value of a blend of two surfactants $A$ and $B$ was determined by the following equation. HLB of blend $=\left(\operatorname{HLB}(A) \times f_{A}\right)-\left(\operatorname{HLB}(A) \times 1-f_{B}\right)$, where, $f_{A}$ and $f_{B}$ is the fraction of surfactant of $A$ and $B$ in the blend respectively.

\section{Bioavailability and Pharmacokinetic analysis}

The rats were selected as models to study the pattern of absorption of formulations into systemic circulation. Twelve healthy male rats weighing 200 - $250 \mathrm{~g}$ were assigned randomly into three groups. The standard rat feed was purchased from National Institute of Nutrition, Hyderabad, India. Each group received one set of formulation. RST powder, $20 \mathrm{mg} / \mathrm{kg}$ body weight was dispersed in $25 \%$ polyethylene glycol and $1 \mathrm{~mL}$ of R-1 and R-2 administered $1 \mathrm{~mL}$ to each of groups orally using dosing needle and similar procedure was conducted for KT, K-1 and K-2 after a washout period of 10 days in the rats. KT was administered at a dose of $10 \mathrm{mg} / \mathrm{kg}$ body weight. The animals were maintained as per the guidelines of the Committee for the Purpose of Control and Supervision of Experiments on Animals (CPCSEA), New Delhi India following approval by the Institutional Animal Ethics Committee (IAEC) of Balaji Institute of Pharmaceutical Sciences (Registration of Establishment: 1694/PO/a/13/ CPCSEA). The blood samples of approximately $0.3 \mathrm{~mL}$ were obtained from the tail vein at $0.5,1,2,3,4,6,8,10,12,18,24,36,48$ and $72 \mathrm{~h}$ for RST, R-1 and R-2 and at 0.5, 1, 2, 3, 4, 6, 8 and $10 \mathrm{~h}$ for KT, K-1 and K-2 formulations under mild ether anesthesia. The collected blood was set to clot for a period of $45 \mathrm{~min}$ and centrifuged at $5000 \mathrm{rpm}$ for $10 \mathrm{~min}$ and the serum was isolated. All samples were stored at $-20{ }^{\circ} \mathrm{C}$ until analyzed using HPLC. The serum sample was further treated with sufficient acetonitrile to precipitate proteins. The formed precipitate was removed using centrifuge at $5000 \mathrm{rpm}$ for $10 \mathrm{~min}$ and supernatant was collected. The supernatant was injected into the HPLC and analyzed as per the HPLC method mentioned above. Pharmacokinetic parameters were analyzed and $\mathrm{T}_{\max }$ and $\mathrm{C}_{\max }$ were determined directly from time (hr) vs. concentration $(\mathrm{ng} / \mathrm{mL})$ curves. The trapezoidal method was used to calculate $\mathrm{AUC}_{0-\mathrm{t}} \cdot \mathrm{AUC}_{0-\infty}$ was determined by: $\mathrm{AUC}_{0-\infty}=\mathrm{AUC}_{0-\mathrm{t}}+\mathrm{C}_{\mathrm{t}} / \mathrm{K}_{\mathrm{e}}$, where $\mathrm{Ke}$ was the apparent elimination rate constant obtained from the terminal slope of the logarithmic plasma concentration vs. time profile (linear regression) in which slope was multiplied with 2.303 and the biological half life $\left(\mathrm{T}_{1 / 2}\right)$ was determined by: $\mathrm{T}_{1 / 2}=0.693 / \mathrm{K}_{\mathrm{e}}$.

\section{In vitro cytotoxicity studies}

The cytotoxic activity of RST and KT nanoformulations were evaluated at various concentrations in K-562 cell lines. In Brief, K-562 cells were cultured at a density of $1 \times 10^{3}$ cells per well in flat-bottomed 96-well plates. After $72 \mathrm{~h}$ of treatment with RST, R-1, R-2, KT, KT-1 and KT-2 at $0.001,0.01,0.1,1,5,10$ and $20 \mu \mathrm{M}$, MTS solution was added to each well, cells were incubated for an additional $2 \mathrm{~h}$ and the cell viability was determined by measuring the absorbance at $490 \mathrm{~nm}$ using an ELISA reader.

\section{RESULTS}

\section{Identification and characterization of active site amino-} acid constraints for DDX3

To identify the active site amino acid constraints, we have retrieved three dimensional structure of DDX3 receptor complexes with AMP (PDB id: 2I4I) from the PDB repository (http://www.rcsb.org). As a first step, hydrogen atoms were added to remove constraints in the crystal structure. To identify the interacting amino acid residues with AMP ligand, a grid was generated with dimensions $27.00 \AA$ x $22.00 \AA$ x $26.00 \AA$ using the molecular cavity detection algorithm. This grid indicates $8 \mathrm{critical}$ hydrogen bond interactions between AMP ligand and Tyr 200, Gln 207, Gly 229, Gly 227, and Thr 231 amino acid residues of DDX3. In the AMP, the pyrimidine portion of adenine and sugar portion of nucleoside interacted with arginine 202, glutamine 207 and the side chain of Tyr 200 respectively, with an average VdW radius of $1.52 \AA$ in the Q Motif. In addition to nucleoside, the phosphate group interacted with Thr 231, Gly 229 and Gly 227 in the P-loop region of the motif I Figure 1A and B.

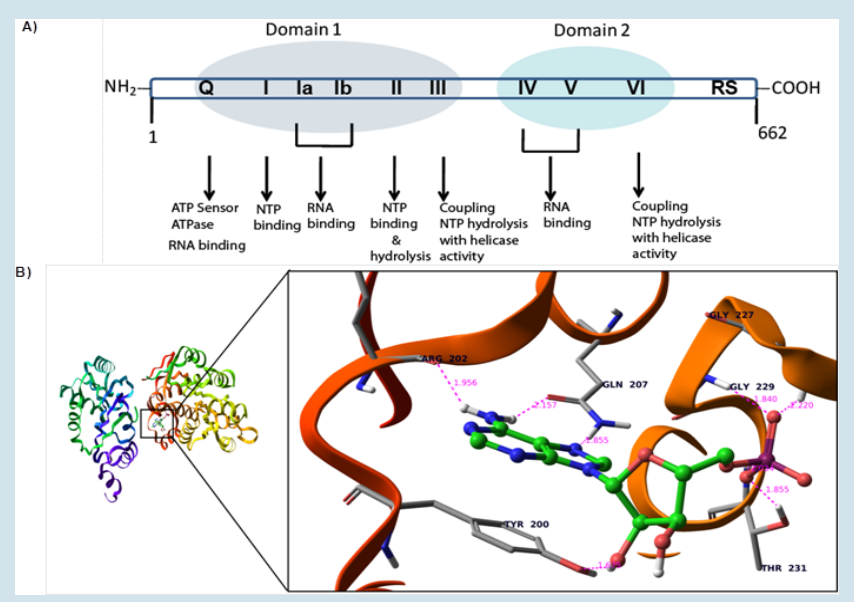

Figure 1: Molecular model of $X$ linked RNA helicase DDX3: A) Evolutionary conserved aminoacid sequence motifs in human DDX3 and their functions. Motif $Q$ acts as a sensor of bound ATP and, thus, regulates ATP binding and hydrolysis. Motifs la, Ib, IV and V bind the substrate RNA. Motifs III and VI promote coupling of NTP binding and hydrolysis to the helicase activity along with variable RS domain B) AMP docked into the ATPase binding site of DDX3. Orange color dotted lines show the hydrogen bond interaction between ligand and active site amino acid atoms. 


\section{Receptor based Molecular docking of FDA approved} drugs Rosuvastatin and Ketorolac against human DDX3

Ketorolac salt is a pyrrolizine carboxylic acid derivative and is structurally related to indomethacin. The generic trademark of Ketorolac salt is Toradol and it belongs to the family of non-steroidal anti-inflammatory drugs (NSAIDs), which are mainly used for the treatment of inflammation and pain after surgery. Very recently, we showed that Ketorolac salt effectively down regulated the expression of DDX3 and inhibited the growth of H357, a human OSCC cell line. Along the lines, we also observed that Ketorolac salt reduced tongue lesions in in-vivo mice models of oral cancer. In search of more potential drug candidates against DDX3, we have performed Induced fit docking (IFD) and molecular dynamic simulations (MDS) using our in-house build FDA approved drug database. Results showed that Rosuvastatin binds stronger as compared to Ketorolac in the AMP binding pocket of dead box. Rosuvastatin has the dock score of -5.4 where as Ketorolac has shown $-4.3 \mathrm{~K} . \mathrm{cal} / \mathrm{mol}$ respectively. Ketorolac during initial Induced Fit Docking (IFD) has shown strong hydrogen bonds with Gly 227, Ser 228, Gly 229 and Thr 231 Figure 2A. In its final stage of molecular dynamic simulations (MDS) it has depicted good hydrogen bond network with amino acids involved in AMP binding. These hydrogen bonds involve Gly 227, Ser 228, Gly 229 and Thr 231. Rosuvastatin has shown better hydrogen bonding network than Ketorolac. The interactions are Gly 227, Ser 228, Gly 229, Thr 231, Lys 230 and Hie 527 Figure 2B. But only important interactions were retained after MDS and the amino acids involved in the network are Gly 227, Gly 229, and Glu 562. Hydrogen bonds were so stable that they have retained in almost $90 \%$ on an average of all MDS frames.

Energy of both the complexes was analyzed and observed that the Rosuvastatin complex was as stable as Ketorolac complex. Up to $30 \mathrm{~ns}$ there was a slight change in the energies of both the complexes but after 30 ns almost similar type of stability in terms of energy was shown. Energy of both the complexes was between -150 to $-50 \mathrm{kcal} / \mathrm{mol}$ Figure $3 \mathrm{~A}$. RMSD generally gives information regarding the average change in the displacement of atoms in the particular frame with respect to the reference frame. Here the RMSD of both the complexes were compared showing that Rosuvastatin complex has less deviation when compared with the Ketorolac complex during the total simulation Figure 3C. Ro-

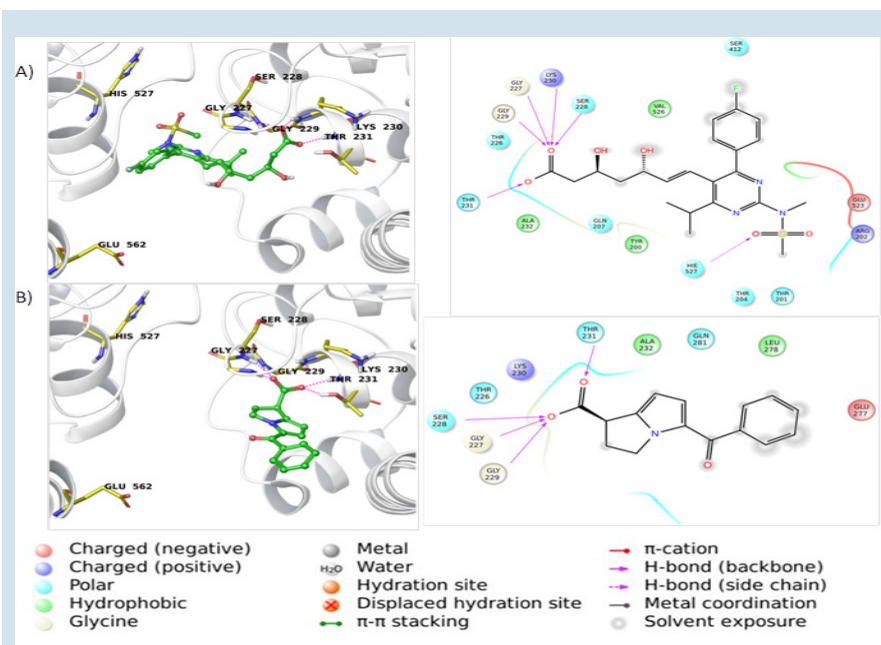

Figure 2: Molecular model for the binding of Rosuvastatin and Ketorolac to DDX3. Left panel, A close-up view of amino acid residues within a 5 A distance of the binding site. Right panel, the ligand interaction is depicted in the binding pocket of the target protein (214I) along with hydrogen and non-hydrogen bond interactions using Lig plot (A) Rosuvastatin (B) Ketorolac. suvastatin complex has exhibited RMSD between 2 to $4 \AA$ and Ketorolac complex has shown 2 to $7 \AA$. RMSF is useful for characterizing local changes along the protein chain Figure 3D indicates that there was much difference in fluctuations between the two complexes. Ketorolac complex has less number of fluctuations and these are between 1 to $4 \AA$ and Rosuvastatin complex has fluctuations up to $7 \AA$ between 400 to 500 residues. Binding pocket does not exist between these amino acids of 400 to 500, so these fluctuations may not have much effect on the stability of the molecule in the binding pocket. Even though the fluctuations may not have any effect on the stability of the complex, there is a need to test our hypothesis. So, hydrogen bond network of both the complexes were observed. Intra molecular hydrogen bond network of both the complexes was almost similar. Number of bonds was in between 300 to 350 Figure 3B. As mention above, the hydrogen bond network maintained by Ketorolac and Rosuvastatin was quite stable and important, because amino acids involved in this network was directly involved in the binding. All the above metrics indicated it was found that Rosuvastatin complex was slightly superior to that of the Ketorolac complex.

\section{Preparation of characterization of RST and KT nanoemulsions}

Initially we measured the specific retention time (RT) for both RST and KT using HPLC analysis. Both drugs displayed different retention time. RST showed RT at $1.65 \pm 0.3 \mathrm{~min}$ and $\mathrm{KT}$ showed RT at $2.1 \pm$ 0.3 min respectively. Following determination of RT values, both the samples were serially diluted from 0.1 micrograms to 15 micrograms and the absorbance values were recorded and they were transported into Excel sheet for the preparation of calibration curve. The linear regression equation for RST and KT were Area $=55.45 \times$ Concentration $(\mathrm{ng} / \mathrm{mL})+$ 18226, $(r 2=0.999)$ and Area $=85.58 \times$ Concentration $(\mathrm{ng} / \mathrm{mL})+20756$, $(r 2=0.999)$ found to be linear in the concentration range of $100-10000$ $\mathrm{ng} / \mathrm{mL}$ with percent relative standard deviation was found to be $<2 \%$. The overlay chromatogram of RST and KT were shown in Figure 4A and Figure 4B. Following determination of the RT values, we prepared two different combinations of RST (R-1 and R-2) and KT (K-1 and K-2) nanoemulsions using two different oils such as Capryol 90 and Maisine 35-1. The HLB of blend was calculated using the surfactant and co-surfactant fraction from total formulation with their actual HLB values and was found to be 13.38. The value greater than 13 indicates that the blend acts as oil-in-water emulsifier and able to form clear solution in water. The preparations were produced mostly clear solution upon
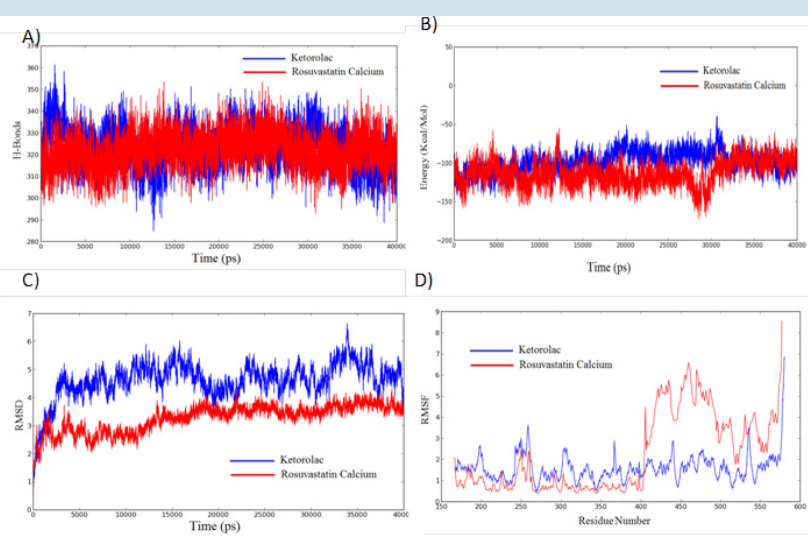

Figure 3: Molecular dynamic trajectories depicted changes during $10 \mathrm{~ns} \mathrm{sim-}$ ulations. A) Energy, B) H-Bonds C) Root mean square deviations RMSD, D) Root mean square fluctuations (RMSF) in the trajectory of DDX3-Ketorolac complex (red) compared with the DDX3-Rosuvastatin (Red). 
Table 2: The polydisperity Index and globule size distribution of RST and KT nanoformulations

\begin{tabular}{ccc}
\hline Samples & PDI \pm SD & Hydrodynamic diameter \pm SD $(\mathrm{nm})$ \\
\hline R1 & 0.07 & 197.7 \\
R2 & 0.084 & 227.2 \\
K1 & 0.142 & 198.7 \\
K2 & 0.085 & 188.4 \\
\hline
\end{tabular}

Table 3: Rheological data of RST and KT formulations at $25^{\circ} \mathrm{C}$

\begin{tabular}{ccccc}
\hline Formulation & Torque (\%) & Shear stress & Shear rate & Mean Viscosity \\
\hline R-1 & $99.5 \pm 0.45$ & $7.23 \pm 0.36$ & 0.17 & $4221 \pm 48.08$ \\
R-2 & $95.2 \pm 0.76$ & $6.75 \pm 0.12$ & 1.22 & $588.1 \pm 12.51$ \\
K-1 & $98.6 \pm 0.14$ & $7.21 \pm 0.25$ & 0.24 & $2941.7 \pm 39.4$ \\
K-2 & $97.5 \pm 0.32$ & $6.85 \pm 0.17$ & 6.73 & $106.3 \pm 4.25$
\end{tabular}

Instrumental fixed input value

dilution. The formulations containing Capryol 90 were showed higher viscosities when compared to formulations containing Maisine 35-1. Capryol 90 in combination with Poloxamer 188/Labrafil M2130CS in R-1 was shown approximately seven times viscosity as compared to $\mathrm{R}-2$. The similar viscosity behaviors were observed as in case of K-1 and $\mathrm{K}-2$ with higher viscosities difference approximately twenty-eight times when related to R-1 and R-2. Both the formulations displayed different polypolydispersity index (PI) and hydrodynamic diameter. The PI for $\mathrm{R}-1, \mathrm{R}-2, \mathrm{~K}-1$ and $\mathrm{K}-2$ was $0.07,0.084,0.142$ and 0.085 respectively. The hydrodynamic diameter of globules for R-1, R-2, K-1 and K-2 was $197.7 \mathrm{~nm}, 227.2 \mathrm{~nm}, 198.7 \mathrm{~nm}$ and 188.4 respectively as shown in Table 2. The rheological parameters such as Torque (\%), Shear stress, Shear rate and Mean Viscosity of RST and KT nanoformulations at $25^{\circ} \mathrm{C}$ was recorded and shown in Table 3.

\section{Solution state stability of formulations at various $\mathrm{pH}$}

To study the solution state stability of RST and KT, The R-1, R-2 and $\mathrm{K}-1, \mathrm{~K}-2$ formulations was exposed to various physiological $\mathrm{pH} 1.2$ ( $\mathrm{pH}$ of the stomach), $\mathrm{pH} \mathrm{4,6.8} \mathrm{(pH} \mathrm{of} \mathrm{instestine),} 7$ and 7.5 conditions for a period of 1, 2 and 24 hrs. As shown in Figure 5, under acidic pHs ( $\leq 4)$ the amount of RST was found to be $92 \%$ and $69 \%$ at 2 and $24 \mathrm{hrs}$ respectively. At higher pHs (4-8) no significant change was observed even at 24 hrs. Unlike RST, the R-1 formulation under acidic pHs $(\leq 4)$ had undergone $30 \%$ and $27 \%$ degradation at $24 \mathrm{hrs}$. Whereas, gradual degradation ( 85 to $50 \%$ ) of R-1 was found at higher pHs (4-8) at $24 \mathrm{hrs}$. Furthermore, R-2 was showed similar characteristics to R-1 in which the maximum drug found at $24 \mathrm{~h}$ is $74 \%$ at $\mathrm{pH}$ 6.8. Taken together, it is clear that the R-1 and R-2 formulations retain stability at $\mathrm{pH}$ 6.8. Error bars were showed as the coefficient of variation in analysis was exceeded $3 \%$. Similarly, the stability study was performed on KT, K-1 and K-2. $\mathrm{KT}$ was found to be quite stable at $\mathrm{pH} 7$ and retains drug content $94 \%$ at $2 \mathrm{~h}$ and $24 \mathrm{~h}$ respectively. As shown in Figure the amount of KT was found to be less than $50 \%$ within $2 \mathrm{hr}$ at $\mathrm{pH} 4$ but not at $\mathrm{pH}$ 1.2. On the other hand, at higher pHs (4-8) it maintained above $70 \%$. Similar profile was observed for $\mathrm{K}-1$, which was stable at $\mathrm{pH} 7$ and $\mathrm{pH} 7.5$ with maximum drug retention $87 \%$ till $24 \mathrm{~h}$. In contrast to K-1, K2 formulation showed great stability between $\mathrm{pH} 1.2$ and $\mathrm{pH} 6.8$. At $\mathrm{pH} 1.2$ and 6.8, K-2 showed maximum drug concentration $75 \%$ and $88 \%$ and degraded at $\mathrm{pH} 7.0$ and pH 7.5 till 24 hrs. Overall, it suggests that K-1 nanoemulsion was stable towards basic $\mathrm{pH}$ while K-2 was stable towards acidic $\mathrm{pH}$.

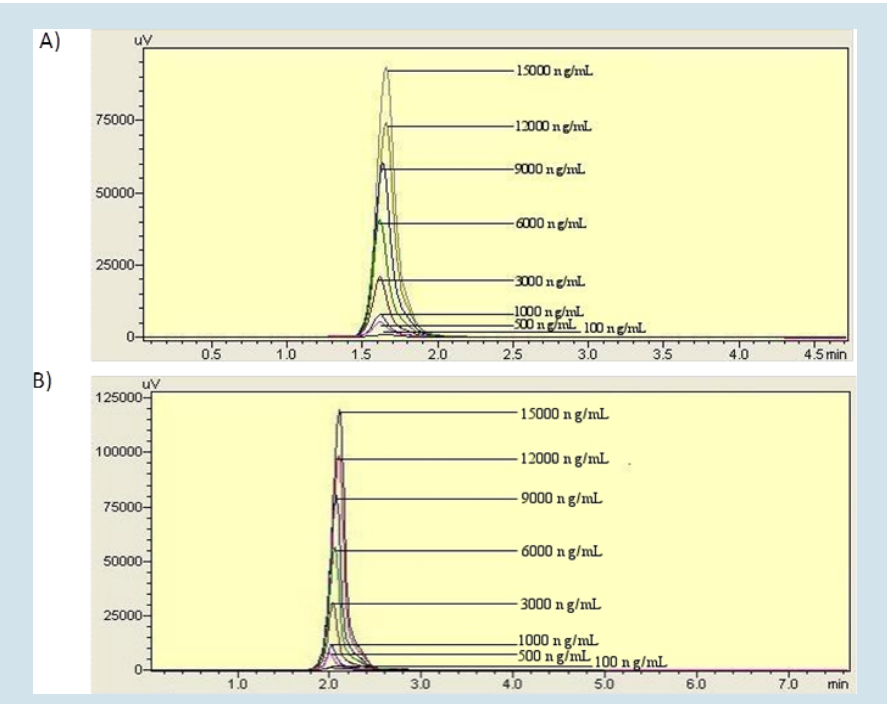

Figure 4: Determination of RST and KT retention times (RT) using HPLC analysis. (A) The overlay chromatogram of RST in acetonitrile:water, 65:35 $(\mathrm{v} / \mathrm{v})$ from $100 \mathrm{ng} / \mathrm{mL}$ to $15000 \mathrm{ng} / \mathrm{mL}$. (B) The overlay chromatogram of KT in methanol:water, 65:35 (v/v) from $100 \mathrm{ng} / \mathrm{mL}$ to $15000 \mathrm{ng} / \mathrm{mL}$.

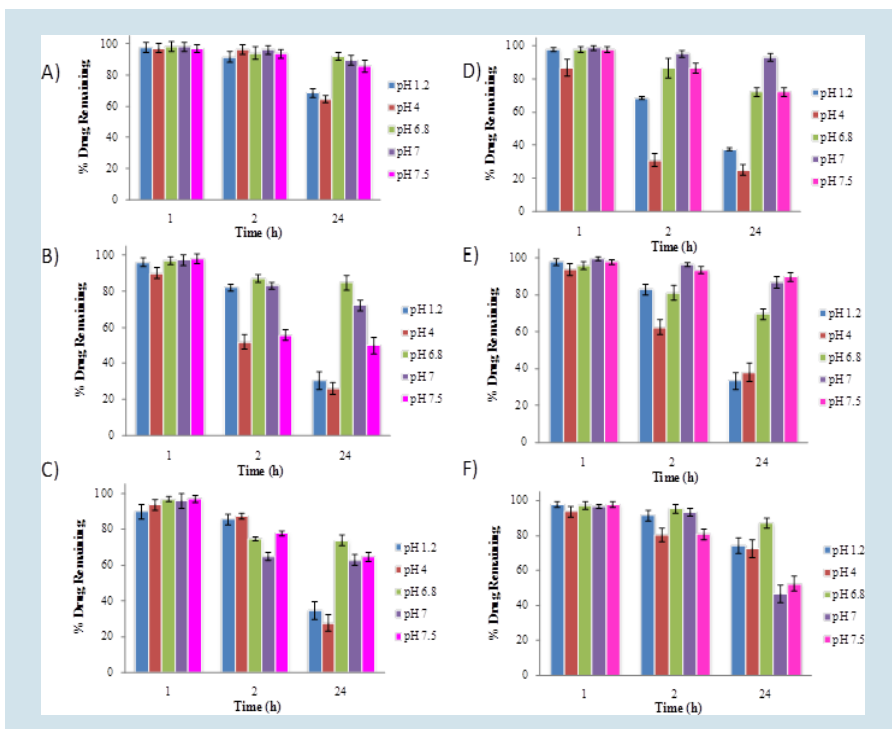

Figure 5: Solution state stability of RST, KT formulations was evaluated at various time periods and $p H$, Data expressed as mean $\pm s d, n=3$. (A) RST (B) R-1 (C) R-2 (D) KT (E) K-1 (F) K-2.

\section{Bioavailability of RST and KT nanoformulations}

As a first step, we assessed the In-vitro drug release by evaluating the permeability of drugs through porcine buccal membrane. The release of RST alone was found to be $18 \%$ which was quite lower when compared to R-1 (46 \%) and R-2 (43 \%) nanoformulations respectively Figure 6A. Similarly release of KT through porcine buccal membrane was found to be $1 \%$ due to its hydrophilic property as compared to K-1 (23\%) and K-2 (21\%) respectively Figure 6B. To measure the bioavailability of RST and KT, their nanoformulations were orally administered into rats. The serum samples from each formulation were subjected to HPLC analysis for bioavailability and pharmacokinetic analysis. As shown in Table 4 R-1 and R-2 exhibited the superior absorption, with higher Cmax $(2537.25 \mu \mathrm{g} / \mathrm{mL}$ and $2744.25 \mu \mathrm{g} / \mathrm{mL})$ and AUC values $(108045.3 \mathrm{~h} \mu \mathrm{g} / \mathrm{mL}$ and $104568.62 \mathrm{~h} \mu \mathrm{g} / \mathrm{mL}$ ), respectively than that of RST alone. The 

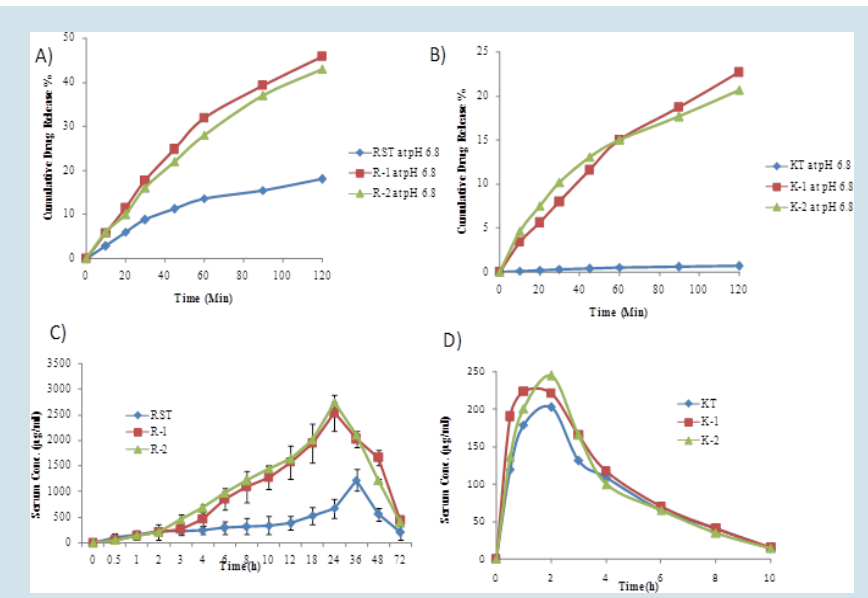

Figure 6: Bioavailability of RST and KT nanoformulations. (A) In vitro drug release kinetics of RST and their formulations across porcine buccal membrane at various time periods and $\mathrm{pH}$, Data expressed as mean, $n=3$ (B) In vitro drug release kinetics of $\mathrm{KT}$ and their formulations across porcine buccal membrane at various time periods and $\mathrm{pH}$. Data expressed as mean, $n=3$ (C) The blood concentration time profile after oral administration of RST and R-1, R-2 to rats (mean $\pm s . d, n=4$ ). The blood concentration time profile after oral administration of KT, K-1 and K-2 to rats (mean \pm s.d, $\mathrm{n}=4$ ).
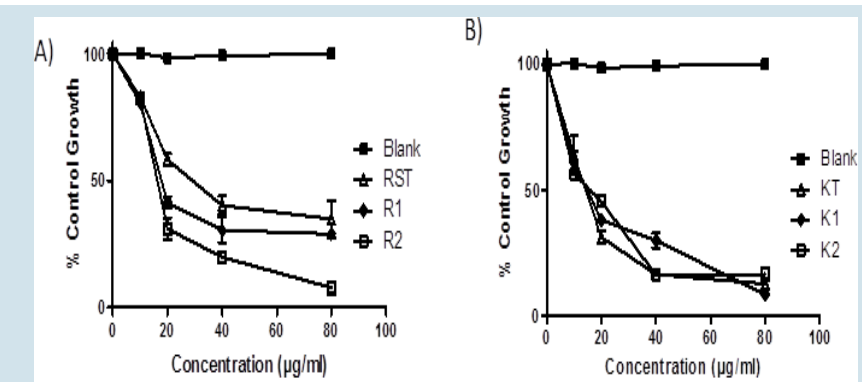

C)
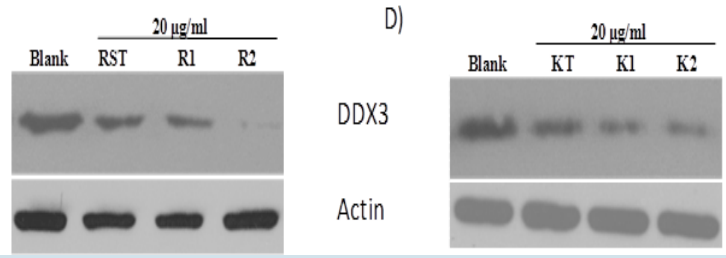

Figure 7: Anti-cancer activity of RST and KT nanoformulations against DDX3 K562 cells were seeded on 6 well culture plates and were treated with indicated concentration of RST and KT nanoformulations. Graphs showing the cancer cell viability against A) RST and R-1, R-2 B) KT and K-1, K-2 C) Western blot depicting the expression of DDX3 against RST, R-1 and R-2 and D) KT, K-1 and K-2.

Table 4: Pharamacokinetic parameters of RST and KT formulations

\begin{tabular}{ccccccc}
\hline Group & RST & R-1 & R-2 & KT & K-1 & K-2 \\
\hline $\mathrm{T}_{1 / 2}(\mathrm{~h})$ & $14.32 \pm 2.17$ & $18.81 \pm 3.26$ & $17.74 \pm 3.62$ & $2.31 \pm 0.54$ & $2.21 \pm 0.61$ & $2.08 \pm 0.42$ \\
$\mathrm{Cmax}(\mu \mathrm{g} / \mathrm{mL})$ & $1219.68 \pm 188.3$ & $2537.25 \pm 355.19$ & $2744.25 \pm 230.82$ & $202.01 \pm 28.7$ & $220.83 \pm 19.36$ & $244.27 \pm 25.04$ \\
$\operatorname{tmax}(\mathrm{h})$ & 36 & 24 & 24 & 1.77 & 1.35 & 1.93 \\
$\mathrm{AUC}(\mathrm{h} \mu \mathrm{g} / \mathrm{mL})$ & $40798.9 \pm 944.74$ & $108045.3 \pm 2445.38$ & $104568.62 \pm 2687.17$ & $925.22 \pm 76.59$ & $1070.29 \pm 81.2$ & $998.93 \pm 64.0$ \\
\hline
\end{tabular}

bioavailability of R-1 and R-2 was 2.5 times greater than RST. KT, K-1 and $\mathrm{K}-2$ were showed slightly different bioavailability profiles and as there was no larger difference in absorption pattern Figure 6C and 6D.

\section{Anti-cancer activity of RST and KT nanoformulations against DDX3}

To determine whether RST and KT -loaded nanoformulations could efficiently kill cancer cells, we carried out an MTS assay following incubation of a human leukemia cancer cell line, K-562 with R1, R2 and K1, K2 nanoformulations. As shown in Figure 7A and B, both RST and KT nanoformulations effectively killed K-562 cells in a dosedependent manner, while equivalent doses of blank nanoformulations had no killing effect. The $\mathrm{IC}_{50}$ value of RST found to be $30 \mu \mathrm{g} / \mathrm{ml}$ and R1 and R2 nanoformulations displayed $18 \mu \mathrm{g} / \mathrm{ml}$. The $\mathrm{IC}_{50}$ value of $\mathrm{KT}$ and their formulations was found to be $17 \mu \mathrm{g} / \mathrm{ml}$. Unlike RST, KT nanoformulations did not show the difference between drug and their formulations. At $\mathrm{IC}_{50}$ concentration, cells were lysed, proteins were extracted, and scored for the expression of DDX3 by immunoblot analysis. As shown in Figure 7C and $\mathrm{D}$ the expression of DDX3 is downregulated in dose dependent manner.

\section{DISCUSSION}

Drug discovery and development is a complex. The development of a new drug requires a major investment of capital, human resources and technological expertise. The cost of inventing and developing a single drug, to get into to market can expect $\$ 350$ million..$^{40}$ Inspite, $95 \%$ of the experimental medicines that are studied in humans fail to be both effective and safe and will not be available for sale due to their side effects. ${ }^{41}$ To overcome these issues, we prepared a FDA approved drug database and performed high Throughput Virtual screening approach against DDX3. Interestingly, we found that Rosuvastatin calcium salt pass the docking process and form a strong hydrogen bond interaction with DDX3 protein as similar to previously discovered DDX3 inhibitor Ketorolac salt. Rosuvastatin calcium (RST), a chemically bis[(E)-7-[4-(4fluorophenyl)-6-isopropyl-2-[methyl-(methyl-sulfonyl) amino] pyrimidin-5-yl] (3R,5S)-3,5-dihydroxyhept-6-enoicacid] calcium salt belongs to the class of 3-hydroxy-3-methylglutaryl-coenzyne A (HMG CoA) reductase inhibitors, in the liver results in lowering blood cholesterol and is used for treatment of hyperlipidemia. ${ }^{42-44}$ RST belongs to the class III compound as per the biopharmaceutical classification system (BCS), which is having low permeability and high solubility. ${ }^{45}$ Apart from said activities of RST, presently statins have been evaluating for anticancer properties. Self-Nanoemulsifying Drug Delivery System of RST has shown antitumor action in Caco-2 cells ${ }^{46}$, Cytotoxic effects on HepG2 cells ${ }^{47}$, inhibits arginase enzyme which is responsible for breast cancer ${ }^{48}$, decreased risk of cancer-related mortality, with a reduction of up to $15 \%{ }^{49}$ The multiple activities of RST and KT have given us new scope for evaluating various cytotoxic effects on various cell lines. Ketorolac Tromethamine (KT) [(+/-)-5(benzoyl)-2,3-dihydro-1N-pyrrolizine1 -carboxylic acid tris hydroxymethylaminomethane salt] is a highly potent drug having analgesic and anti-inflammatory activity, and being used for acute pain, post-operative analgesia..$^{50,51} \mathrm{KT}$ has $\mathrm{pKa}$ of 3.5 and 
having partition coefficient (n-octanol/water) of 0.26 . KT is completely absorbed after oral administration. The half-life of S- and R-enantiomer is $2.5 \pm 0.4 \mathrm{~h}$ and $5 \pm 1.7 \mathrm{~h}$ respectively and the half-life for the racemic $\mathrm{KT}$ is within the range of 5 to $6 \mathrm{~h}$ (http://www.rxlist.com/toradol-drug. $\mathrm{htm}$ ). Presently, various marketed preparations available such as Acular LS, Acuvail, Acular, Omidria to treat various inflammatory conditions. Recently our group was found that KT is acting against oral cancer cell lines ${ }^{30}$, KT was evaluated for chemoprevention of oropharyngeal leukoplakia and later the study was concluded that permeation of KT is required to be improved in delivering drug from keratinized layer to the basement membrane of oral mucosa due to its polar nature. ${ }^{52}$

Hydrophobic compounds like RST and KT are not easy to handle in order to maximize clinical utility. One strategy to improve the bioavailability of the drugs is to make nanoemulsions. Nanoemulsions are oil-in water dispersions, the better choice to improve dissolution and bioavailability. ${ }^{46,47}$ Several lipid based formulations such as saquinavir (Fortovase ${ }^{\oplus}$, Roche Pharmaceuticals, NJ, USA), ritonavir (Norvir ${ }^{\oplus}$, Abbott Laboratories, IL, USA), cyclosporin (Neoral ${ }^{\oplus}$, Novartis Pharmaceutical Ltd., Surrey, UK) were approved by regulatory agencies and given impetus for development of lipid based formulations for the improved oral delivery of poorly water soluble drugs. Nanoemulsion drug delivery have been reported to improve the bioavailability of hydrophobic drugs very effectively ${ }^{53,54}$, increased in vivo performance of anticancer drugs, e.g., dacarbazine ${ }^{55}$ and camptothecin. ${ }^{56}$ In our present study, we have formulated RST and KT nanoemulsions as a carrier for new DDX3 helicase inhibitor. Stability of nanoemulsions at various $\mathrm{pH}$ were performed for the optimized formulation, permeation across porcine - buccal membrane, further evaluated the significance of nanoemulsions of RST and KT in anticancer activity in K-562 cell lines. The buccal absorption of R-1, R-2, $\mathrm{K}-1$ and $\mathrm{K}-2$ were found to be higher when compared to respective active pharmaceutical ingredients. Short term $\mathrm{pH}$ stability study indicated that the formulations are suitable for oral administration. The oral absorption of RST was only $20 \%$ limited by the dissolution rate and decrease of the particles size plays an essential role in improving the bioavailability of these drugs. KT has received itself good bioavailability, K-1 and K-2 was showed similar pattern as like KT. R-2 was showed absolute cytotoxic effect at $80 \mu \mathrm{g} / \mathrm{mL}$ in K-562 cell lines with no further development of resistant cells which was found to be high when compared to RST and R-1. Similarly, K-2 was showed cytoxicity in K-562 cell lines than KT. From the above data, we hope that R-2 showed better bioavailability pattern and this nanoemulsion displayed a good anti-cancer activity against K-562 leukemia cells. Taken together, we conclude that RST and KT formed a hydrogen bond interaction with RNA helicase, DDX3 and their nanoemulsions showed anti-cancer activity against K-562 leukemia cells by inhibiting the expression of DDX3. These nanoemulsions also displayed good oral bioavailability at $\mathrm{pH} 6.8$.

\section{CONCLUSION}

Rosuvastatin and Ketorolac Nanoformulations downregulate the expression of DDX3 and that this nanoformulations can be used as an ideal drug candidate to treat DDX3 associated disorders.

\section{ACKNOWLEDGEMENT}

We are thankful to Gattefosse (St-Priest, France), BASF Corporation North America, Abitec Corporation (Janesville, USA) for supply of gift samples of various oils and surfactants and also thankful to Nosch labs Pvt. Ltd., India for providing the Ketorolac salt. This work was partially supported by a grant from the Department of Biotechnology, Government of India (BT/PR6743/NNT/28/614/2012), and University Grants Commission (RA-2012-14-GE-ANP-2088) to Mahendran Botlagunta.

\section{CONFLICT OF INTEREST}

There are no conflicts of interest.

\section{ABBREVIATION USED}

RST: Rosuvastatin; KT: Ketorolac; MDS: Molecular Dynamic Simulation; HLB: Hydrophile-lipophile balance.

\section{REFERENCES}

1. Umate P. Genome-wide analysis of lipoxygenase gene family in Arabidopsis and rice. Plant Signaling and Behavior. 2011;6(3):335-8

2. Kim YS, Lee SG, Park SH, Song K. Gene structure of the human DDX3 and chromosome mapping of its related sequences. Molecules and Cells. 2001;12(2):209-14.

3. Hogbom M, Collins R, Den Berg S, Jenvert RM, Karlberg T, Kotenyova TA, et al. Crystal structure of conserved domains 1 and 2 of the human DEAD-box helicase DDX3X in complex with the mononucleotide AMP. J Mol Biol. 2007;372(1):150-9.

4. Gee SL, Conboy JG. Mouse erythroid cells express multiple putative RNA helicase genes exhibiting high sequence conservation from yeast to mammals. Gene. 1994;140(2):171-7.

5. Botlagunta M, Vesuna F, Mironchik Y, Raman A, Lisok A, Winnard $P$, et al. Oncogenic role of DDX3 in breast cancer biogenesis. Oncogene. 2008;27(28):3912-22.

6. Sun M, Song L, Li Y, Zhou T, Jope RS. Identification of an antiapoptotic protein complex at death receptors, Cell Death Differ. 2008;15(12):1887-1900.

7. Celia-Terrassa T, Meca-Cortes O, Mateo F, De Paz AM, Rubio N, Arnal-Estape A, et al. Epithelial-mesenchymal transition can suppress major attributes of human epithelial tumor-initiating cells. J Clin Invest. 2012;122(5):1849-68.

8. Sarrio D, Rodriguez-Pinilla SM, Hardisson D, Cano A, Moreno-Bueno G, Palacios J. Epithelial-mesenchymal transition in breast cancer relates to the basal-like phenotype. Cancer Res. 2008;68(4):989-97.

9. Talbot LJ, Bhattacharya SD, Kuo PC. Epithelial-mesenchymal transition, the tumor microenvironment, and metastatic behavior of epithelial malignancies. Int $J$ Biochem Mol Biol. 2012;3(2):117-36.

10. Teicher BA, Dupuis NP, Robinson MF, Kusumoto T, Liu M, Menon K. Reduced oxygenation in a rat mammary carcinoma post-radiation and reoxygenation with a perflubron emulsion/carbogen breathing, in vivo. 1994;8(1):125-31.

11. Reynolds TY, Rockwell S, Glazer PM. Genetic instability induced by the tumor microenvironment. Cancer Res. 1996;56(24):5754-7.

12. Brizel DM, Scully SP, Harrelson JM, Layfield LJ, Bean JM, Prosnitz LR. Tumor oxygenation predicts for the likelihood of distant metastases in human soft tissue sarcoma. Cancer Res.1996;56(5):941-3.

13. Semenza GL. HIF-1: mediator of physiological and pathophysiological responses to hypoxia. J Appl Physiol. 2000;88(4):1474-80.

14. Semenza GL. O2-regulated gene expression: transcriptional control of cardiorespiratory physiology by HIF-1. J Appl Physiol. 2004;96(3):1173-7; discussion 1170-2.

15. Botlagunta M, Krishnamachary B, Vesuna F, Winnard PT, Bol GM, Patel $A H_{\text {, }}$ et al. Expression of DDX3 is directly modulated by hypoxia inducible factor-1 alpha in breast epithelial cells. PloS one. 2011;6(3):e17563.

16. Chang PC, Chi CW, Chau GY, Li FY, Tsai YH, Wu JC, et al. DDX3, a DEAD box RNA helicase, is deregulated in hepatitis virus-associated hepatocellular carcinoma and is involved in cell growth control. Oncogene. 2006;25(14):1991-2003.

17. Chao $\mathrm{CH}$, Chen $\mathrm{CM}$, Cheng $\mathrm{PL}$, Shih JW, Tsou AP, Lee YH. DDX3, a DEAD box RNA helicase with tumor growth-suppressive property and transcriptional regulation activity of the $\mathrm{p} 21$ waf1/cip1 promoter, is a candidate tumor suppressor. Cancer Res. 2006;66(13):6579-88.

18. Garbelli A, Beermann S, Di Cicco G, Dietrich U, Maga G. A motif unique to the human DEAD-box protein DDX3 is important for nucleic acid binding, ATP hydrolysis, RNA/DNA unwinding and HIV-1 replication, PloS one. 2011;6(5):e19810.

19. Yedavalli VS, Neuveut C, Chi YH, Kleiman L, Jeang KT. Requirement of DDX3 DEAD box RNA helicase for HIV-1 Rev-RRE export function. Cell. 2004;119(3):381-92

20. Kondaskar A, Kondaskar S, Kumar R, Fishbein JC, Muvarak N, Lapidus RG Hosmane, Novel, Broad Spectrum Anti-Cancer Agents Containing the Tricyclic 5:7:5-Fused Diimidazodiazepine Ring System. ACS Med Chem Lett. 2010:2(3):252-6

21. Yedavalli VS, Zhang N, Cai H, Zhang P, Starost MF, Hosmane RS. Ring expanded nucleoside analogues inhibit RNA helicase and intracellular human immunodeficiency virus type 1 replication. J Med Chem. 2008;51(16):5043-51.

22. Hosmane R, Raman V and Kumar R. Fused Di imidazodiazepine Compounds and Methods of Use and Manufacture Thereof. USA. 2009.

23. Maga G, Flchi A, Garbelli A, Belfiore M, Witvrouw F, Manetti M. Pharmacophore modeling and molecular docking led to the discovery of inhibitors of human immunodeficiency virus-1 replication targeting the human cellular 
aspartic acid-glutamic acid-alanine-aspartic acid box polypeptide 3. J Med Chem. 2008;51 (21):6635-8.

24. Kondaskar A, Kondaskar S, Kumar R, Fishbein JC, Muvarak N, Lapidus RG. Broad spectrum Anti-Cancer agents containing the Tricyclic 5:7:5-Fused Diimidazodiazepine Ring System. ACS Med Chem Lett. 2010;2(3):252-6.

25. Gazzerro P, Proto MC, Gangemi G, Malfitano AM, Ciaglia E, Pisanti S. Pharmacological actions of statins: a critical appraisal in the management of cancer. Pharmacol Rev. 2012;64(1):102-46.

26. Evans WE, McLeod HL. Pharmacogenomics drug disposition, drug targets, and side effects. NEJM. 2003;348(6):538-49.

27. Kinch MS, Haynesworth A, Kinch SL, Hoyer D. An overview of FDA-approved new Molecular Entities: 1827-2013, Drug discovery today. 2014;19(8):1033-9.

28. Kinch MS, Merkel J, Umlauf S. Trends in pharmaceutical targeting of clinical indications: 1930-2013, Drug discovery today. 2014;19(11):1682-5.

29. T MK, RV, B K, B S, KV, N R, et al. Preparation and Characterization of Rosuvastatin Calcium Nanoemulsions. Lat Am J Pharm. 2013;32(10):1445-51.

30. Samal SK, Routray S, Veeramachaneni GK, Dash R, Botlagunta M. Ketorolac salt is a newly discovered DDX3 inhibitor to treat oral cancer. Sci Rep. 2015;5:9982.

31. Guo Z, Mohanty U, Noehre J, Sawyer TK, Sherman W, Krilov G. Probing the alpha-helical structural stability of stapled p53 peptides: molecular dynamics simulations and analysis. Chemical Biology and Drug Design. 2010;75(4):34859.

32. Maple JR, Cao Y, Damm W, Halgren TA, Kaminski GA, Zhang LY, et al. A Polarizable Force Field and Continuum Solvation Methodology for Modeling of Protein-Ligand Interactions. J Chem Theory Comput. 2005;1 (4):694-715.

33. Krajewski WW, Collins R, Holmberg-Schiavone L, Jones TA, Karlberg T, Mowbray SL. Crystal structures of mammalian glutamine synthetases illustrate substrate-induced conformational changes and provide opportunities for drug and herbicide design. J Mol Biol. 2008;375(1):217-28.

34. Sherman W, Beard HS, Farid R. Use of an induced fit receptor structure in virtual screening, Chemical Biology and Drug Design. 2006;67(1):83-4.

35. Sandri G, Rossi S, Ferrari F, Bonferoni MC, Muzzarelli C, Caramella C. Assessment of chitosan derivatives as buccal and vaginal penetration enhancers, Eur J Pharm Sci. 2004;21(2):351-9.

36. Lefebvre DE, Venema K, Gombau L, Valerio JR LG, Raju J, Bondy GS, et al. Utility of models of the gastrointestinal tract for assessment of the digestion and absorption of engineered nanomaterials released from food matrices. Nanotoxicology. 2015;9(4):523-42.

37. Patel VF, Liu F, Brown MB. Modeling the oral cavity: in vitro and in vivo evaluations of buccal drug delivery systems. J Controlled Release. 2012;161(3):74656.

38. Manganaro AM, Wertz PW. The effects of permeabilizers on the in vitro penetration of propranolol through porcine buccal epithelium. Military Medicine. 1996;161(11):669-72.

39. Squier CA. The permeability of oral mucosa. Crit Rev Oral Biol Med. 1991;2(1):13-32.

40. Liu C, Constantinides PP, Li Y. Research and development in drug innovation: reflections from the 2013 bioeconomy conference in China, lessons learned and future perspectives. Acta Pharm Sin B. 2014;4(2):112-9.

41. Hartung T. Look back in anger - what clinical studies tell us about preclinical work. Altex. 2013;30(3):275-91.

42. Brown WV, Bays HE, Hassman DR, McKenney J, Chitra R, Hutchinson H, et al. Efficacy and safety of rosuvastatin compared with pravastatin and simvastatin in patients with hypercholesterolemia: a randomized, double-blind, 52-week trial. Am Heart J. 2002;144(6):1036-43.

43. Jones PH, Davidson MH, Stein EA, Bays HE, McKenney JM, Miller E. Comparison of the efficacy and safety of rosuvastatin versus atorvastatin, simvastatin, and pravastatin across doses (STELLAR Trial). Am J Cardiol. 2003;92(2):152-60.

44. Martin PD, Warwick MJ, Dane AL, Hill SJ, Giles PB, Phillips PJ, et al. Metabolism, excretion, and pharmacokinetics of rosuvastatin in healthy adult male volunteers. Clin Ther. 2003:25(11):2822-35.

45. Bergman E, Matsson EM, Hedeland $\mathrm{M}$, Bondesson $\mathrm{U}$, Knutson $\mathrm{L}$, Lennernas $\mathrm{H}$. Effect of a single gemfibrozil dose on the pharmacokinetics of rosuvastatin in bile and plasma in healthy volunteers. J Clin Pharmacol. 2010;50(9):1039-49.

46. Kamel AO, Mahmoud AA. Enhancement of human oral bioavailability and in vitro antitumor activity of rosuvastatin via spray dried self-nanoemulsifying drug delivery system. J Biomed Nanotechnol. 2013;9(1):26-39.

47. El Sharkawi FZ, El Shemy HA, Khaled HM. Possible anticancer activity of rosuvastatine, doxazosin, repaglinide and oxcarbazepin. Asian Pac J Cancer Prev. 2014;15(1):199-203.

48. Erbas $\mathrm{H}, \mathrm{Bal} \mathrm{O}$, Cakir E. Effect of rosuvastatin on arginase enzyme activity and polyamine production in experimental breast cancer. Balkan Med J. 2015;32(1):89-95

49. Nielsen SF, Nordestgaard BG, Bojesen SE. Statin use and reduced cancerrelated mortality. The New England Journal of Medicine. 2012;367(19)1792-802.

50. Bartfield JM, Kern AM, Raccio-Robak N, Snyder HS, Baevsky RH. Ketorolac tromethamine use in a university-based emergency department. Acad Emerg Med. 1994;1 (6):532-8.

51. Wong HY, Carpenter RL, Kopacz DJ, Fragen RJ, Thompson G, Maneatis TJ. A randomized, double-blind evaluation of ketorolac tromethamine for postoperative analgesia in ambulatory surgery patients. Anesthesiology. 1993;78(1):6-14

52. Mulshine JL, Atkinson JC, Greer RO, Papadimitrakopoulou VA, Waes C, Rudy S, et al. Lippman, R. Frye, PF Cavanaugh, Jr. Randomized, double-blind, placebocontrolled phase $\mathrm{Ilb}$ trial of the cyclooxygenase inhibitor ketorolac as an ora rinse in oropharyngeal leukoplakia. Clinical Cancer Research: An Official Journal of the American Association for Cancer Research. 2004;10(5):1565-73.

53. Vyas TK, Shahiwala A, Amiji MM. Improved oral bioavailability and brain transport of Saquinavir upon administration in novel nanoemulsion formulations. International Journal of Pharmaceutics. 2008;347(1):93-101.

54. Kuo F, Subramanian B, Kotyla T, Wilson TA, Yoganathan S, Nicolosi RJ. Nanoemulsions of an anti-oxidant synergy formulation containing gamma tocophero have enhanced bioavailability and anti-inflammatory properties. Int J Pharm. 2008;363(1):206-13

55. Kakumanu S, Tagne JB, Wilson TA, Nicolosi RJ A nanoemulsion formulation of dacarbazine reduces tumor size in a xenograft mouse epidermoid carcinoma model compared to dacarbazine suspension. Nanomedicine: Nanotechnology. Biology, and Medicine. 2011; 7(3):277-83.

56. Han M, He CX, Fang QL, Yang XC, Diao YY, Xu DH. A novel camptothecin derivative incorporated in nano-carrier induced distinguished improvement in solubility, stability and anti-tumor activity both in vitro and in vivo. Pharm Res. 2009;26(4):926-35.

Article History: Submission Date : 29-04-2017 ; Revised Date : 06-05-2017; Acceptance Date : 19-07-2017.

Cite this article: Bheemanapally K, Thimmaraju MK, Kasagoni S, Thatikonda P, Akula S, kodamala KR, Kakarla L, Gummadi SB and Botlagunta M. In vitro AntiCancer Activity of Rosuvastatin and Ketorolac Nanoformulations against DDX3. J Young Pharm. 2017;9(4):537-44. 